\title{
Cyclic Deformation Behaviour and Its Optimization at Elevated Temperature
}

\author{
Patiphan Juijerm ${ }^{1}$ and Igor Altenberger ${ }^{2}$ \\ ${ }^{1}$ Department of Materials Engineering, Kasetsart University \\ ${ }^{2}$ WIELAND-WERKE AG, Central Laboratory, Research \& Development \\ 1Thailand \\ ${ }^{2}$ Germany
}

\section{Introduction}

Recently, low-weight components are particularly required for environmental, ecological and economical aspects. Therefore, light-weight metals/alloys are frequently mentioned and selected for many applications where low density and high strength to weight ratios are an important consideration. Consequently, development and improvement in the field of light-weight alloys can be seen continuously for advanced applications in automotive as well as aerospace industries, where many applications involved about elevated temperature are increase. One of the most important light-weight metals is aluminium and its alloys which possess many attractive characteristics including excellent corrosion resistance in most environments, reflectivity, high strength and stiffness to weight ratio, good formability, weldability and recycling potential. Certainly, these advantageous properties make them ideal candidates to replace heavier materials (steel or copper) for several industries. Therefore, mechanical behaviour of aluminium alloys becomes more and more important, especially under cyclic loading at room and elevated temperature due to failures occurring in machinery components are almost entirely fatigue failures. Accordingly, cyclic deformation behaviour of aluminium alloys was investigated and also improved by wellknown mechanical surface treatments, e.g. shot peening, deep rolling and laser shock peening. Deep rolling is one of the most well-known mechanical surface treatment methods and exhibits a great depth of near-surface work hardening state and compressive residual stresses serving to inhibit or retard fatigue crack initiation as well as crack growth (Scholtes, 1997; Wagner, 1999; Schulze 2005). However, the outstanding benefits of the deep rolling treatment are insecure under high-loading and/or elevated temperature conditions due to occurring relaxation of near-surface macroscopic compressive residual stresses as well as work hardening states. In this case, a detrimental effect on the fatigue lifetime can be expected, particularly in smooth, soft and mechanically surface treated materials, such as deep rolled aluminium alloys because their fatigue lifetime depends significantly on the stability of near-surface compressive residual stresses as well as work hardening states (Altenberger, 2003). Therefore, the main purpose of this research is to investigate systematically the cyclic deformation behavior of the deep rolled aluminium alloys at room and elevated temperature. Wrought aluminium alloys AA5083 and AA6110 were selected 
and investigated in this research representing typical non-precipitation-hardenable and precipitation-hardenable aluminium alloys, respectively. The precipitation-hardened aluminium wrought alloy AA6110 (Al-Mg-Si-Cu) was heat treated to the as quenched, under-, peak- and over-aged conditions. The cyclic deformation as well as fatigue behavior have been investigated systematically at room and elevated temperature. The effects of static/dynamic precipitation occurring during fatigue at elevated temperatures was analyzed and discussed by means of the cyclic deformation and $\mathrm{s} / \mathrm{n}$ curves. To optimize the fatigue behavior and performance, deep rolling was performed a room temperature. Residual stresses and work hardening states near the surface of the deep rolled condition were characterized by X-ray diffraction methods. Depth profiles of residual stresses, full width at half maximum (FWHM) values of the X-ray diffraction peaks and microhardness near the surface of the deep rolled conditions are presented. The cyclic deformation behavior and $\mathrm{s} / \mathrm{n}$ curves of deep rolled specimens have been investigated by stresscontrolled fatigue tests at room and elevated temperatures up to $250{ }^{\circ} \mathrm{C}$ and compared to the non deep rolled condition as a reference. The effect of deep rolling on the fatigue lifetime and residual stresses under high-loading and/or elevated-temperature conditions will be discussed.

\section{Materials and experimental procedure}

The aluminium wrought alloy AA5083 was delivered as warm rolled sheet with a thickness of $15 \mathrm{~mm}$. The chemical composition of this alloy is $0.4 \% \mathrm{Si}, 0.4 \% \mathrm{Fe}, 0.1 \% \mathrm{Cu}$, $0.4-1 \% \mathrm{Mn}, 4.5 \% \mathrm{Mg}, 0.05-0.25 \% \mathrm{Cr}, 0.25 \% \mathrm{Zn}, 0.15 \% \mathrm{Ti}$ and $\mathrm{Al}$ balance (all values in $w t \%)$. The aluminium wrought alloy AA6110 was delivered as extruded bars with a diameter of $34 \mathrm{~mm}$. The chemical composition of this alloy is $0.86 \mathrm{Si}, 0.19 \mathrm{Fe}, 0.45 \mathrm{Cu}, 0.46$ $\mathrm{Mn}, 0.78 \mathrm{Mg}, 0.17 \mathrm{Cr}, 0.02 \mathrm{Zn}, 0.01 \mathrm{Ti}$ and $\mathrm{Al}$ balance (all values in wt\%). Aluminium alloy AA6110 specimens were solution heat treated in an argon atmosphere furnace at $525{ }^{\circ} \mathrm{C}$ for 30 minutes followed by water quenching to room temperature. Quenched specimens were aged immediately at $160{ }^{\circ} \mathrm{C}$ for 1,12 and 168 hours ( 1 week), which will be designated as under-, peak- and over-aged, respectively in the following discussion. Important mechanical properties of investigated aluminium alloys are given in table 1 . Cylindrical specimens with a diameter of $7 \mathrm{~mm}$ and a gauge length of $15 \mathrm{~mm}$ were prepared. The loading direction during fatigue investigations corresponds to the extrusion direction of the bar or sheet. For deep rolling, a hydraulic rolling device with a $6.6 \mathrm{~mm}$ spherical rolling element and a pressure of 100 bar (80 bar for the as-quenched condition) was applied at room temperature. Tension-compression fatigue tests were conducted with a servohydaulical testing device under stress control without mean stress $(\mathrm{R}=-1)$ and with a test frequency of $5 \mathrm{~Hz}$. Strain was measured using capacitative extensometers. Residual stress depth profiles were determined by successive electrolytical material removal using the classical $\sin ^{2} \Psi$-method with $\mathrm{Cu}-\mathrm{Ka}$ radiation at the $\{333\}$ planes and $1 / 2 \mathrm{~s}_{2}=19.77 \times 10^{-5} \mathrm{~mm}^{2} / \mathrm{N}$ as elastic constant. Near-surface work hardening was characterized by the full width at half maximum (FWHM) values of the X-ray diffraction peaks and by microhardness measurements. All residual stresses and FWHM-values were measured in longitudinal direction of the specimens. No stress correction was carried out after electrolytical material removal of surface layers. 


\begin{tabular}{|c|c|c|c|c|c|}
\hline & Ageing parameter & $\begin{array}{c}\text { Hardness } \\
{[\mathrm{HV}]}\end{array}$ & $\begin{array}{c}\mathrm{O}_{0.2} \\
{[\mathrm{MPa}]}\end{array}$ & $\begin{array}{c}\text { UTS } \\
{[\mathrm{MPa}]}\end{array}$ & $\begin{array}{c}\text { Elongation } \\
{[\%]}\end{array}$ \\
\hline AA5083 & - & 90 & 185 & 295 & 19 \\
\hline $\begin{array}{c}\text { as-quenched } \\
\text { AA6110 }\end{array}$ & - & 84 & 155 & 302 & 33 \\
\hline $\begin{array}{c}\text { under-aged } \\
\text { AA6110 }\end{array}$ & $160^{\circ} \mathrm{C}, 1$ hour & 125 & 292 & 400 & 28 \\
\hline $\begin{array}{c}\text { peak-aged } \\
\text { AA6110 }\end{array}$ & $160^{\circ} \mathrm{C}, 12$ hours & 139 & 425 & 455 & 22 \\
\hline $\begin{array}{c}\text { over-aged } \\
\text { AA6110 }\end{array}$ & $160^{\circ} \mathrm{C}, 168$ hours & 120 & 393 & 413 & 24 \\
\hline
\end{tabular}

Table 1. Some mechanical properties of aluminium alloys AA5083 and AA6110

\section{Cyclic deformation behaviour at room temperature}

The fatigue lifetimes at room temperature of aluminium alloys AA5083 and AA6110 in different ageing treatments are shown as non-statistically evaluated s/n-curves in Fig. 1. Due to quite similar hardnesses of the under-, peak- and over-aged conditions, no significant differences in fatigue lifetime between under-, peak- and over-aged AA6110 at room temperature are seen. Obviously, for these investigations of AA6110, if the hardness is significantly lower as in the as-quenched condition, fatigue lifetimes are lower when compared with aged conditions in low cycle fatigue regime. Although fatigue lifetime of the under-, peak- and over-aged conditions show no significant differences, their cyclic deformation behaviour was distinctly different because of the different size and structure of precipitates within the matrix. Cyclic deformation behaviour of aluminium alloys is associated by dislocation-precipitation and/or dislocation-dislocation interaction during cyclic deformation (Srivatsan \& Coyne, 1986; Srivatsan, 1991). The AA5083 and as-quenched AA6110 contain mainly solute atoms (no effective precipitates are assumed). Consequently, cyclic hardening indicating increasing dislocation densities and dislocation-dislocation interaction during cyclic deformation was observed at room temperature as shown in Fig. 2. The under-aged AA6110 exhibited also cyclic hardening during fatigue tests at room temperature. It can be mentioned that dislocation densities increased and dislocationdislocation interactions occurred in the under-aged AA6110, although precipitates $\beta^{\prime \prime}$ in the under-aged AA6110 could be expected. However, these precipitates in the under-aged AA6110 were possibly so small and not fully effective. Consequently, for impeding dislocation movement, dislocations could still move easier through the precipitates as well as strain fields induced by remained solute atoms or atomic clusters and then dislocationdislocation interactions occurred during cyclic deformation. On the other hand, if the major precipitates $\beta^{\prime \prime}$ in AA6110 alloy are ordered, coherent, semi-coherent and effective within the aluminium matrix, the to-and-fro motion of dislocations during cyclic deformation through the ordered precipitates causes a mechanical local disordering or scrambling of the atoms in the precipitates. The structure of the precipitates becomes disordered and degraded. The hardening due to ordering is lost, therefore cyclic softening is observed in the peak- and over-aged AA6110 as depicted in Fig. 3. The analogous cyclic hardening as well 
as cyclic softening mechanism of precipitation-hardened aluminium alloys was also reported in (Srivatsan \& Coyne, 1986; Srivatsan, 1991). In general, the stress amplitude does not strongly affect the shape of the cyclic deformation curve, i.e. the AA5083, as-quenched and under-aged AA6110 exhibit still cyclic hardening and the peak- and over-aged AA6110 show cyclic softening. However, an increase of plastic strain amplitudes during fatigue tests at room temperature was measured with increasing stress amplitude, consequently, fatigue lifetimes decreased taking into account the Coffin-Manson law (Manson, 1966; Coffin, 1954).

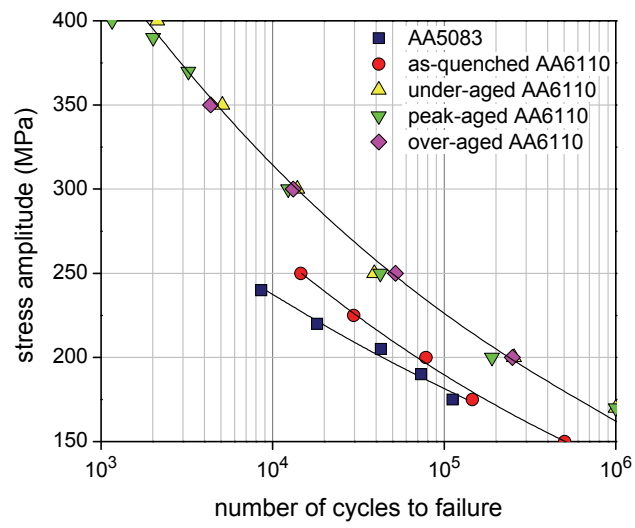

Fig. 1. Non-statistically evaluated s/n-curves of AA5083 and differently aged AA6110 at room temperature

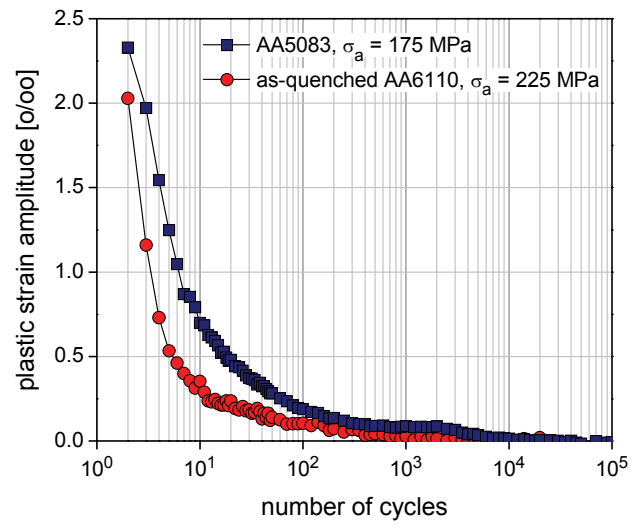

Fig. 2. Cyclic deformation curves of AA5083 and as-quenched AA6110 at an applied stress amplitude of 175 and $225 \mathrm{MPa}$, respectively

\section{Cyclic deformation behaviour at elevated temperature}

Fatigue lifetimes of the AA5083 and AA6110 usually decreased with increasing test temperature due to an increase of plastic strain amplitudes of cyclic deformation curves with increasing test temperature (at the same stress amplitude). It could be attributed to easy glide, climb and cross slip of edge and screw dislocations at elevated temperatures. 
Non-statistically evaluated s/n-curves of peak-aged AA6110 at elevated temperatures are presented in Fig. 4 as an example. As expected, an increasing test temperature shifts s/ncurves to lower fatigue strength as well as lifetime. The fatigue lifetime of the peak-aged condition at room temperature at an applied stress amplitude of $250 \mathrm{MPa}$ is about 42,500 cycles, whereas for the same applied stress amplitude at a temperature of $250{ }^{\circ} \mathrm{C}$, it is reduced to only roughly 5,500 cycles. Normally, fatigue lifetimes decrease with increasing temperature, however during fatigue tests in the temperature range $100-200{ }^{\circ} \mathrm{C}$ the static/dynamic precipitation occurs and affects more or less the fatigue lifetimes of the asquenched AA6110 as shown in Fig. 5. The fatigue lifetime at room temperature of the asquenched condition for an applied stress amplitude of $225 \mathrm{MPa}$ is about 30,000 cycles, whereas at a test temperature of $100{ }^{\circ} \mathrm{C}$ for the same applied stress amplitude, the fatigue lifetime increases to approximately 50,000 cycles. But for a test temperature of $250{ }^{\circ} \mathrm{C}$, lower fatigue lifetimes of approximately 12,000 cycles were measured. Therefore, the fatigue

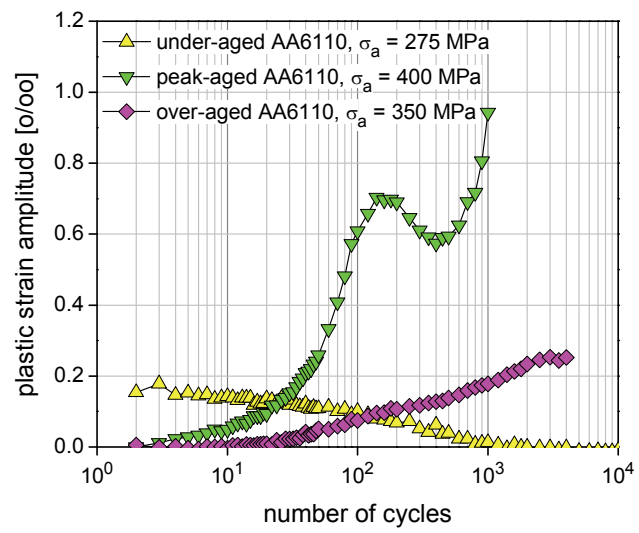

Fig. 3. Cyclic deformation curves of under-, peak- and over-aged AA6110 at an applied stress amplitude of 275,400 and $350 \mathrm{MPa}$, respectively

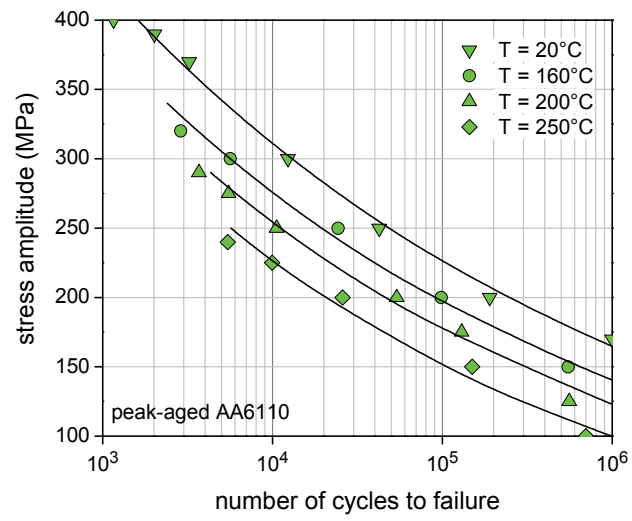

Fig. 4. Non-statistically evaluated s/n-curves of peak-aged AA6110 for different test temperatures 


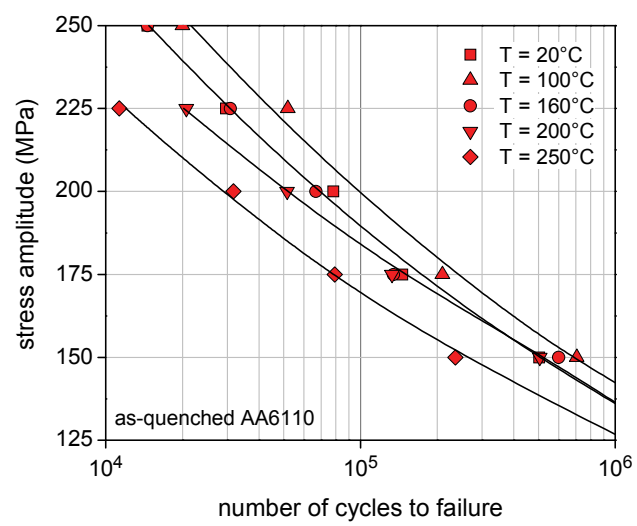

Fig. 5. Non-statistically evaluated s/n-curves of as-quenched AA6110 for different test temperatures
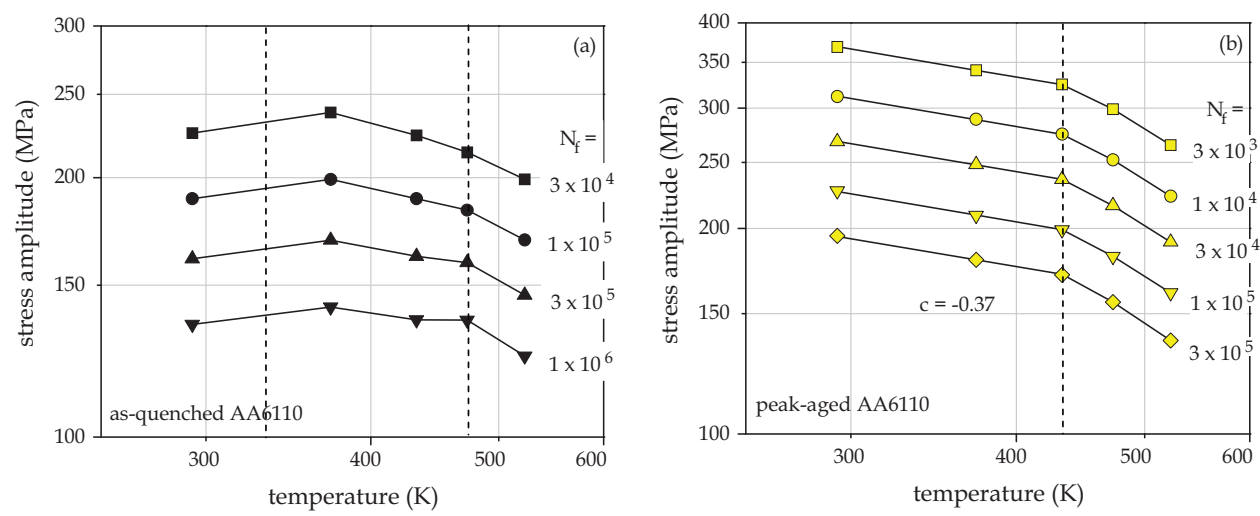

Fig. 6. Temperature dependence of stress amplitudes in a bi-logarithmic scale of (a) asquenched and (b) peak-aged AA6110

behavior at elevated temperature of the as-quenched and peak-aged AA6110 is meaningful and ought to be analyzed in more details. For elevated temperature, if log-log scales and Kelvin temperature are used, the Basquin equation can be generalized to the following form (Kohout, 2000).

$$
\sigma_{a}=a^{*} N_{f}^{b} T^{c}
$$

where $\mathrm{a}^{*}$ is a materials constant which differs from the constant a in equation (1), c is also a materials constant, named the temperature sensitivity parameter and can be defined by the equation.

$$
c=\left.\frac{\partial \log \sigma_{a}}{\partial \log T}\right|_{N_{f}=\text { const. }}
$$


From equation (2), the temperature dependence of stress amplitude was plotted in a bilogarithmic scale for a given number of cycles to failure $\left(3 \times 10^{3}, 10^{4}, 3 \times 10^{4}, 10^{5}\right.$ and $\left.3 \times 10^{5}\right)$ of the as-quenched AA6110 in Fig. 6a. Stress amplitudes for given numbers of cycles increase at a test temperature of $100{ }^{\circ} \mathrm{C}$ and then slightly decrease with increasing test temperature up to approximately $200{ }^{\circ} \mathrm{C}$. It can be attributed to the effect of static/dynamic precipitates on the fatigue lifetimes of the as-quenched AA6110 at elevated temperatures. Consequently, a materials constant $\mathrm{c}$ of the polished as-quenched AA6110 for fatigue tests at elevated temperatures can not be determined using equation (2). On the other hand, for the peak- and over-aged AA6110, two important aspects were detected: firstly, the experimental results can be fitted by equation (2) for test temperatures lower than about $160-200{ }^{\circ} \mathrm{C}$; secondly, the decrease in stress amplitude as well as fatigue strength at temperatures of 200 and particularly $250{ }^{\circ} \mathrm{C}$ (see Fig. 6b) indicates that creep probably begins to play a dominant role at these temperatures. Cyclic creep can be described by monitoring positive mean strains during stress-controlled fatigue test. Therefore, mean strains during fatigue tests were measured and plotted for different test temperatures in Fig. 7 which depicts values of mean strains during fatigue tests of the peak-aged AA6110 at an applied stress amplitude of $300 \mathrm{MPa}$ for different test temperatures as an example. Clearly, for test temperatures less than $160{ }^{\circ} \mathrm{C}$, no significant mean strains during fatigue tests of the polished peak-aged AA6110 were observed. Whereas at a test temperature of $200{ }^{\circ} \mathrm{C}$ at a similar applied stress amplitude of $300 \mathrm{MPa}$, positive mean strains were measured during fatigue test. Moreover, these mean strains became more and more pronounced with increasing number of cycles. Elevated temperature affects not only on the fatigue lifetime, but also on the cyclic deformation curves of aluminium alloy AA6110. The as-quenched AA6110 exhibits cyclic hardening during fatigue tests at elevated temperature up to $250{ }^{\circ} \mathrm{C}$ at a number of cycles to failure of about 10,000 cycles (duration about 1 hour). It can be probably said that the static/dynamic precipitates of the as-quenched AA6110 were not fully effective during this investigation in spite of a relatively high temperature of $250{ }^{\circ} \mathrm{C}$ (but relatively short investigated period). Thus, dislocations could still move easier through the precipitates as well as strain fields induced by remaining solute atoms or clusters and then dislocationdislocation interactions occurred during cyclic deformation. Cyclic deformation curves of

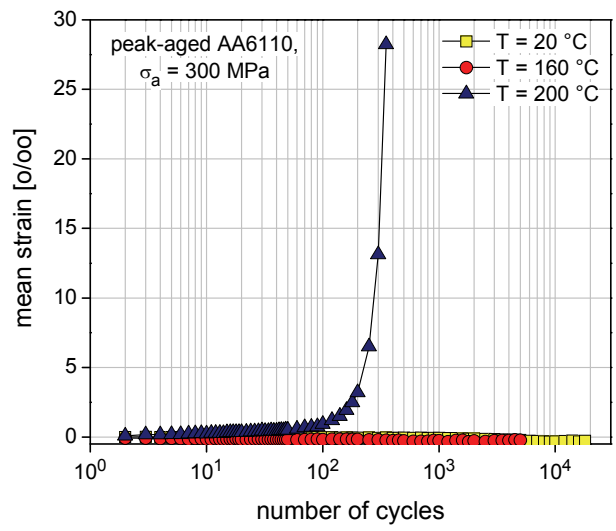

Fig. 7. Mean strains during fatigue tests of peak-aged AA6110 at a stress amplitude of 300 $\mathrm{MPa}$ for different test temperatures 


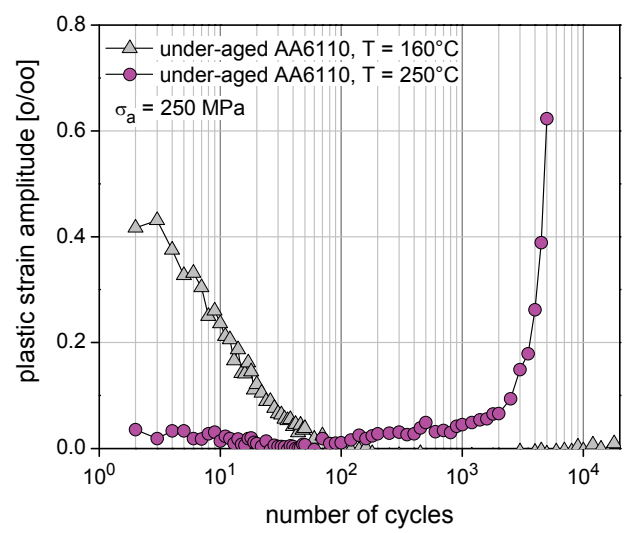

Fig. 8. Cyclic deformation curves of under-aged AA6110 at a stress amplitude of $250 \mathrm{MPa}$ for test temperatures of 160 and $250{ }^{\circ} \mathrm{C}$

the under-aged condition during fatigue tests at elevated temperature up to $200{ }^{\circ} \mathrm{C}$ show also a similar behavior. However, a change of cyclic deformation curve of the under-aged AA6110 from cyclic hardening at test temperatures less than $200{ }^{\circ} \mathrm{C}$ to cyclic softening at a test temperature of $250^{\circ} \mathrm{C}$ was observed as shown in Fig. 8. It possibly indicates that during fatigue tests at a test temperature of $250{ }^{\circ} \mathrm{C}$, precipitates of the under-aged AA6110 were altered to be more effective in size and coherent as well as semi-coherent within the aluminium matrix. Then, during cyclic deformation, dislocations moved to-and-fro through the coherent/semi-coherent precipitates causing a mechanical local disordering or scrambling of the atoms in the precipitates. The structure of the precipitates became disordered and degraded. The hardening due to ordering was lost, and consequently cyclic softening was observed for this situation. For the peak- and over-aged AA6110, cyclic softening still occurred during fatigue tests at test temperatures up to $250{ }^{\circ} \mathrm{C}$ and their plastic strain amplitudes during fatigue tests increased with increasing test temperature.

\section{Effects of deep rolling on cyclic deformation behaviour}

Important affecting factors on the cyclic deformation behaviour of the aluminium alloys AA5083 and AA6110 have been considered and discussed, e.g. influence of precipitation, stress amplitude and temperature. However, for the deep rolled condition, additional factors as surface smoothening, near-surface compressive residual stresses, work hardening states and increased hardness values (see in Figs. 9-10 as examples) induced by deep rolling affect significantly the cyclic deformation behaviour. These beneficial effects of the deep rolling treatment enhance the fatigue lifetime of aluminium alloys due to they serve to inhibit or retard fatigue crack initiation as well as fatigue crack growth (Scholtes, 1997; Wagner, 1999; Schulze 2005). Lower plastic strain amplitude of the deep rolled condition was normally observed during fatigue tests at a given temperature (see in Fig. 11 as an example). Hence, a fatigue lifetime enhancement should be expected taking into account the Coffin-Manson law. Non-statistically evaluated s/n-curves of deep rolled AA5083 and AA6110 at room temperature are presented in Fig. 12. At elevated temperature, the fatigue lifetimes as well as strengths of the deep rolled AA5083 and differently aged AA6110 


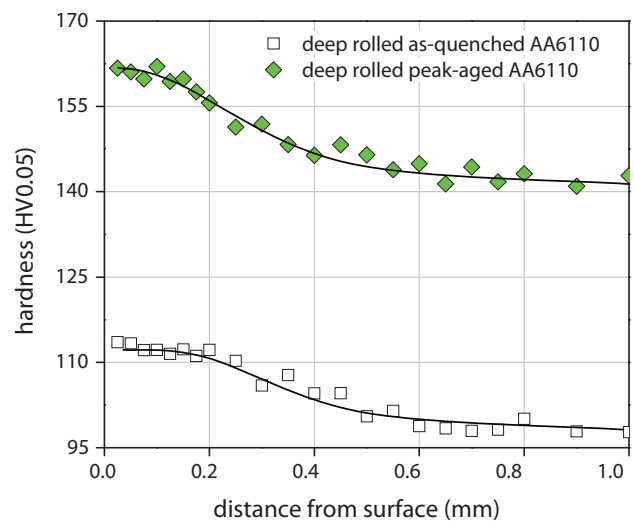

Fig. 9. Near surface hardness values of the deep rolled as-quenched and peak-aged AA6110
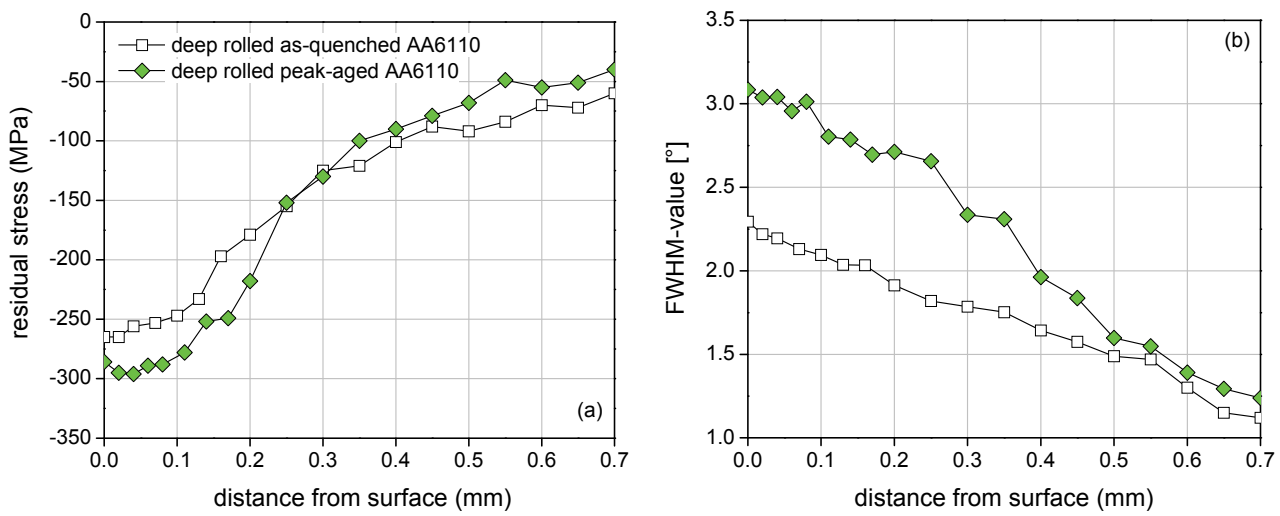

Fig. 10. Depth-profiles of near-surface (a) compressive residual stresses and (b) FWHMvalues of the deep rolled as-quenched and peak-aged AA6110

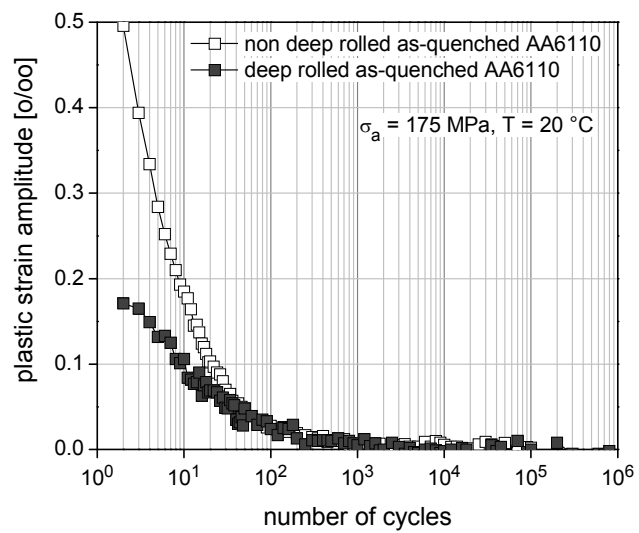

Fig. 11. Cyclic deformation curves of the non- and deep rolled as-quenched AA6110 at stress amplitude of $175 \mathrm{MPa}$ at room temperature 


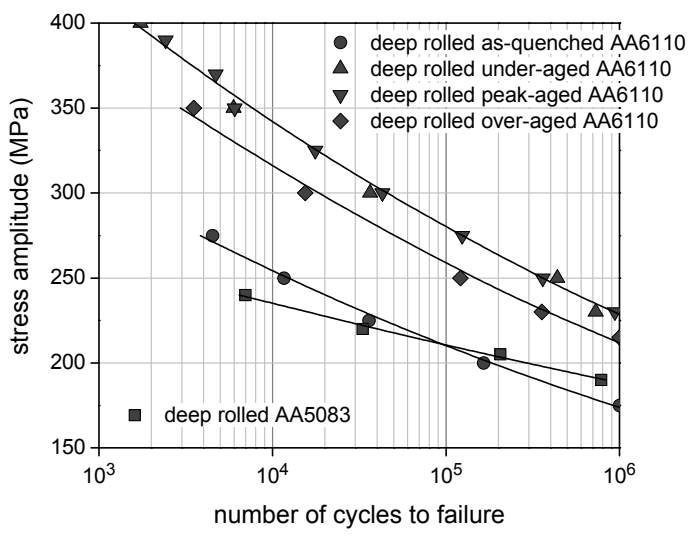

Fig. 12. Non-statistically evaluated s/n-curves of deep rolled AA5083 and differently aged AA6110 at room temperature

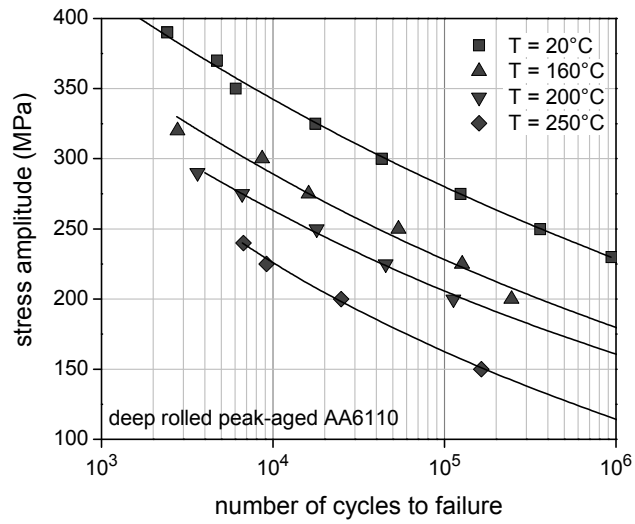

Fig. 13. Non-statistically evaluated s/n-curves of deep rolled peak-aged AA6110 for different test temperatures

decreased undoubtedly under cyclic loading as shown an example in Fig. 13 depicting nonstatistically evaluated $\mathrm{s} / \mathrm{n}$ curves of deep rolled peak-aged AA6110 for different test temperatures. It indicates that the fatigue lifetimes of the deep rolled aluminium alloys depend strongly on the state of near surface compressive residual stresses and work hardening. At elevated temperature, dislocations can glide, climb as well as cross slip easier including high diffusion rates at elevated temperature. Consequently, residual stress relaxation is more and more pronounced for this loading situation. Moreover, a more complicated situation can be expected for the deep rolled as-quenched and under-aged AA6110, where occurring static/dynamic precipitation and residual stress relaxation took place simultaneously during elevated temperature fatigue tests. The competition between occurring static/dynamic precipitates which can enhance the fatigue life and residual stress relaxation phenomena which normally deteriorate the fatigue lifetime of the deep rolled condition should be analyzed and discussed. Equation (2) was used again to analyze the temperature sensitivity parameter, c. The temperature dependence of stress amplitude was 
plotted in a bi-logarithmic scale for a given number of cycles to failure of the deep rolled asquenched and peak aged AA6110 as presented in Figs. 14a and 14b. The materials constants c of the deep rolled as-quenched AA6110 of -0.22 was detected although static/dynamic precipitation occurred during fatigue tests at elevated temperatures. For the deep rolled peak-aged AA6110 (see Fig 14b), the materials constant c $(c=-0.50)$ can be determined. It indicates that the fatigue lifetimes of the deep rolled condition are dominated by the effects of the residual stress relaxation and not by the effects of static/dynamic precipitation for the deep rolled as-quenched AA6110. As compared to the non deep rolled condition, fatigue lifetime enhancement through deep rolling was observed certainly but only for all low and intermediate applied stress amplitudes for given test temperatures. It is possible that nearsurface compressive residual stresses as well as work hardening states relax significantly under relatively high loading and/or elevated temperature (Löhe \& Vöhringer, 2002). Consequently, deep rolling becomes probably ineffective under severe loading conditions. To simplify this state, s/n-curves at test temperatures of 20 and $160{ }^{\circ} \mathrm{C}$ of the non deep rolled
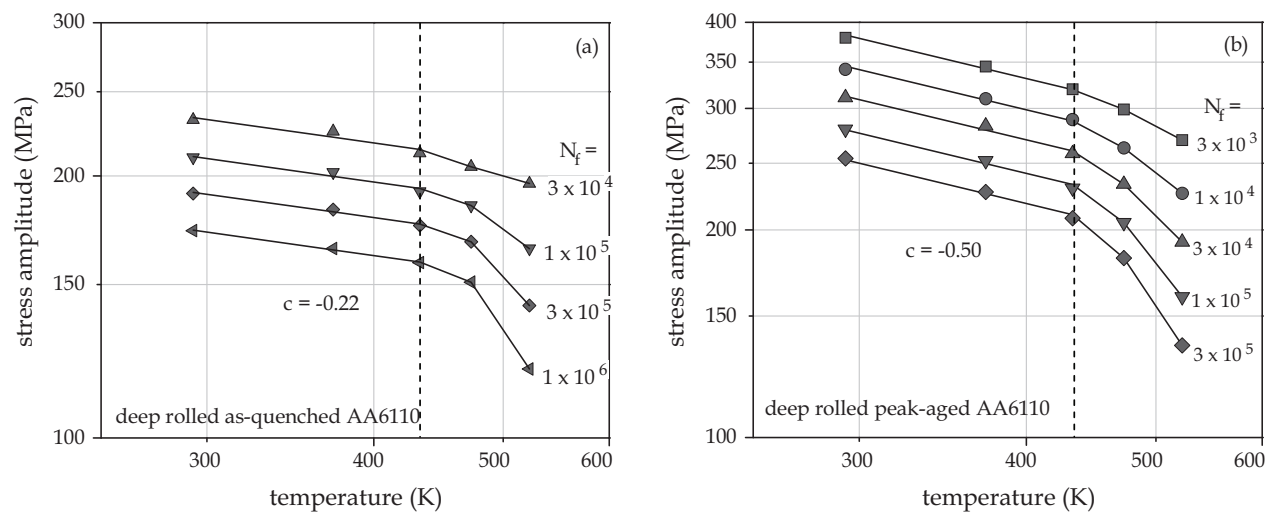

Fig. 14. Temperature dependence of stress amplitudes in a bi-logarithmic scale of deep rolled (a) as-quenched and (b) peak-aged AA6110

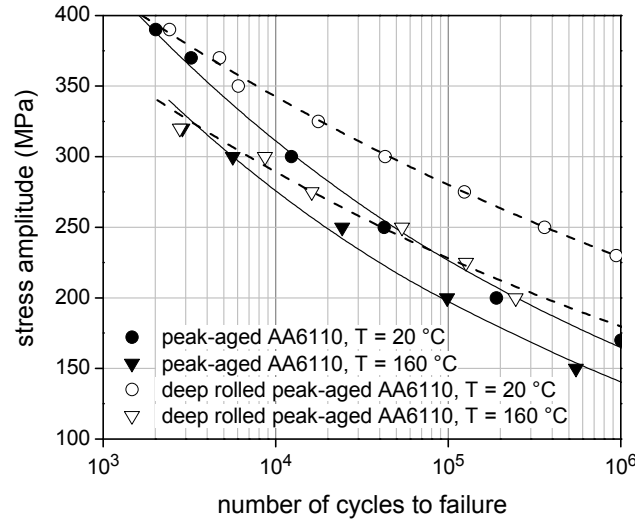

Fig. 15. Non-statistically evaluated s/n curves of non- and deep rolled peak-aged AA6110 for test temperatures of 20 and $160^{\circ} \mathrm{C}$ 

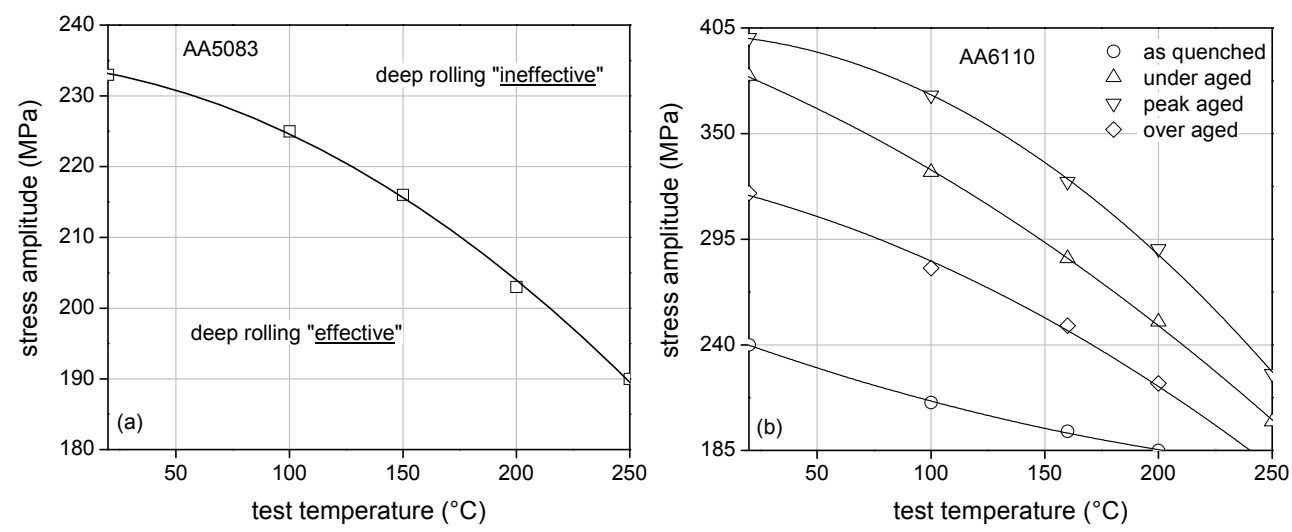

Fig. 16. Effective boundary lines of deep rolling treatment of (a) AA5083, (b) differently aged AA6110 plots as a function of stress amplitude and test temperature

and deep rolled peak-aged AA6110 were plotted in one diagram as an example in Fig. 15. For AA5083 and other differently aged AA6110, analogous diagrams were found also. Relaxation of residual stresses as well as work hardening states during cyclic loading at room and elevated temperatures may be a cause for the different effectiveness of deep rolling. From Fig. 15, intersection points between s/n-curves of the non deep rolled and deep rolled conditions for each test temperatures can be seen. Therefore, all intersection points were summarized and plotted in stress amplitude-temperature diagrams for AA5083 and different aged AA6110 as shown in Figs 16a and b.

\section{Residual stress stability}

Hitherto, it can be mentioned that too high stress amplitudes and temperatures are certainly the main detrimental effects on the fatigue lifetime of deep rolled aluminium alloys. This implies that at certain (very high) stress amplitude for a given (very high) test temperature, deep rolling becomes ineffective due to the near surface residual stresses and work hardening states were relaxed as well as unstable. Fatigue lifetimes of the non- and deep rolled conditions were plotted and compared in one diagram to illustrate the effectiveness of the deep rolling as shown in Fig. 17. Residual stresses and work hardening states (FWHMvalues) were measured during fatigue tests. Several test conditions which were located both in the regions where deep rolling is effective and ineffective (see Figs. 16a and b) were investigated as shown in table 2. It was seen obviously that the fatigue lifetimes of the deep rolled conditions which deep rolling is ineffective were not improved as compared to the non deep rolled condition. The stability as well as instability of compressive residual stresses and work hardening states can be seen clearly when their values before and after fatigue tests were plotted in one diagram in Figs. 18a and b. From Figs 17, 18a and b, a correlation between the effectiveness of deep rolling and the stability of compressive residual stresses as well as work hardening states is obvious. The deep rolling treatment can enhance the fatigue lifetime of aluminium alloys although residual stresses relaxed 
significantly up to about 70\% (see Figs. 17 and 18a). On the other hand, the effectiveness of deep rolling depends strongly on the stability of near-surface work hardening represented by the FWHM-value. If FWHM-values decrease more than about 5\%, deep rolling becomes ineffective (see Figs. 17 and 18b). Therefore, it can be concluded that the near-surface work hardening state is the major factor influencing the fatigue lifetime of the deep rolled aluminium alloys. Deep rolling can enhance the fatigue lifetime of aluminium alloys AA5083 and differently aged AA6110 through the stability of work hardening states. A possible explanation for this behaviour is that the fatigue damage is primarily crack initiation and thus work hardening controlled for deep rolled aluminium alloys.

\begin{tabular}{|c|c|c|c|c|c|}
\hline Number & Alloy & Condition & Test temperature $\left({ }^{\circ} \mathrm{C}\right)$ & $\sigma_{a}(\mathrm{MPa})$ & Cycles \\
\hline 1 & AA5083 & as received & 20 & 205 & $100,000^{* *}$ \\
\hline $2^{*}$ & AA5083 & as received & 20 & 240 & $2,500 * *$ \\
\hline 3 & AA6110 & as-quenched & 160 & 150 & 1,000 \\
\hline $4^{*}$ & AA6110 & as-quenched & 160 & 250 & 1,000 \\
\hline 5 & AA6110 & under-aged & 20 & 250 & $175,000^{* *}$ \\
\hline 6 & AA6110 & under-aged & 20 & 350 & $3,000^{* *}$ \\
\hline $7^{*}$ & AA6110 & under-aged & 20 & 400 & $400 * *$ \\
\hline 8 & AA6110 & under-aged & 200 & 175 & 1,000 \\
\hline 9* & AA6110 & under-aged & 200 & 300 & 1,000 \\
\hline 10 & AA6110 & peak-aged & 20 & 250 & $150,000^{* *}$ \\
\hline 11 & AA6110 & peak-aged & 20 & 300 & $20,000^{* *}$ \\
\hline 12 & AA6110 & peak-aged & 20 & 350 & $3,500^{* *}$ \\
\hline $13^{*}$ & AA6110 & peak-aged & 20 & 400 & $250^{* *}$ \\
\hline 14 & AA6110 & peak-aged & 160 & 200 & 1,000 \\
\hline 15 & AA6110 & peak-aged & 160 & 300 & 1,000 \\
\hline $16^{*}$ & AA6110 & peak-aged & 200 & 300 & 100 \\
\hline 17 & AA6110 & over-aged & 20 & 250 & $50,000^{\star *}$ \\
\hline $18^{*}$ & AA6110 & over-aged & 20 & 350 & $1,000^{* *}$ \\
\hline 19 & AA6110 & over-aged & 160 & 200 & 1,000 \\
\hline $20^{*}$ & AA6110 & over-aged & 160 & 290 & 1,000 \\
\hline
\end{tabular}

* deep rolling is ineffective, ${ }^{* *}$ at half the number of cycles to failure

Table 2. Test conditions for residual stress and work hardening stability and effectiveness of deep rolling treatment investigations 


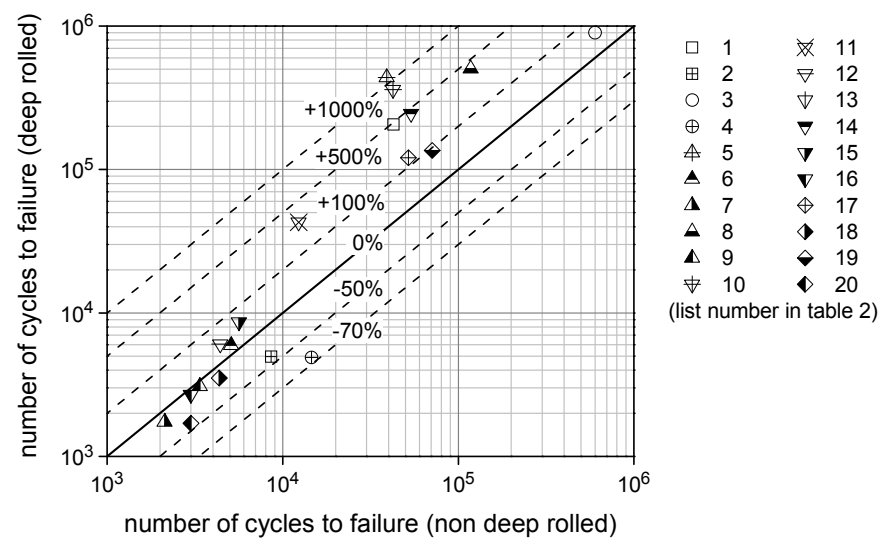

Fig. 17. Effectiveness of deep rolling treatment for several test conditions (in table 2)
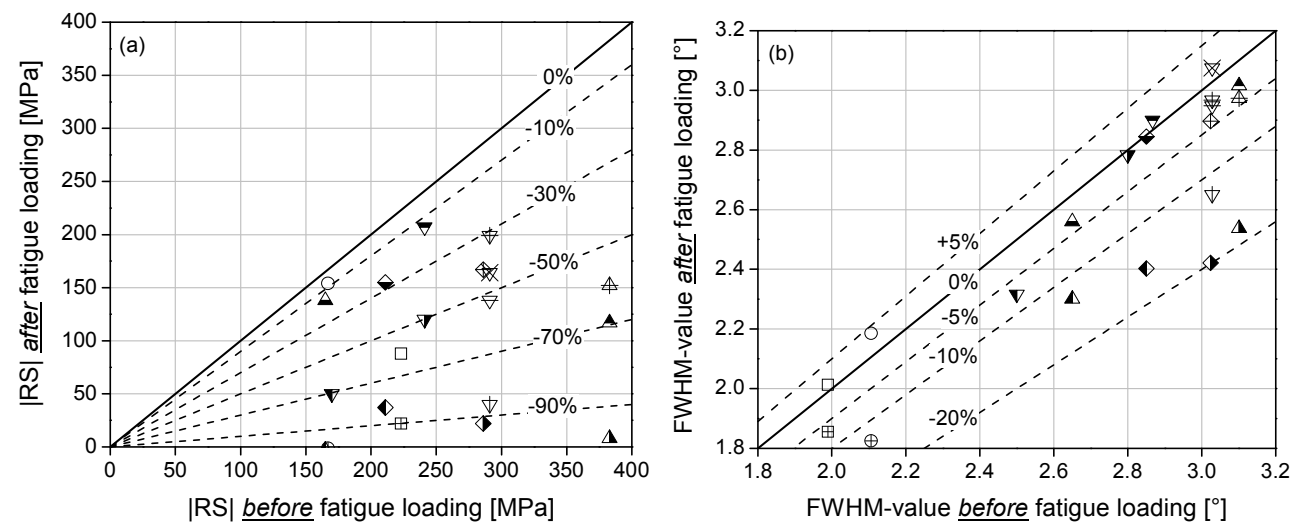

Fig. 18. Relaxation of (a) residual stresses and (b) work hardening states (FWHM values) for several test conditions (in table 2)

\section{Acknowledgements}

The authors would like to express sincere thanks to the German Science Foundation (DFG) and to the Faculty of Engineering, Kasetsart University, Thailand, for financial support for Dr.-Ing. I. Altenberger and Dr.-Ing. P. Juijerm, respectively.

\section{Conclusion}

The cyclic deformation behavior of aluminium alloys AA5083 and differently aged AA6110 at room and elevated temperature under stress control has been successfully investigated 
and discussed. The effects of deep rolling on cyclic deformation behavior has been systematically studied and clarified both at room and elevated temperatures as compared to the non deep rolled condition as a reference. Residual stress as well as work hardening stability has been investigated. From this research, the conclusions can be addressed as presented below

1. Fatigue lifetimes of the non- and deep rolled conditions depend strongly on stress amplitude and temperature. Their fatigue lives decrease with increasing stress amplitude and/or temperature. An exception was found for the as-quenched AA6110, where a slight increase of fatigue life at a test temperature of $100^{\circ} \mathrm{C}$ was observed due to occurring static/dynamic precipitation during investigations.

2. The cyclic deformation behaviour of aluminium alloys AA5083 and AA6110 are governed by dislocation-dislocation and/or dislocation-precipitation interactions during cyclic loading. Aluminium alloys AA5083, as-quenched and under-aged AA6110 exhibit cyclic hardening due to increasing dislocation and dislocationdislocation interactions during cyclic loading, whereas peak- and over-aged AA6110 show cyclic softening due to the to-and-fro motion of dislocations through the ordered precipitates during cyclic deformation causing a mechanical local disordering or scrambling of the atoms in the precipitates, leading to a loss of hardening (Srivatsan \& Coyne, 1986; Srivatsan, 1991).

3. Deep rolling enhances fatigue lifetimes of aluminium alloys AA5083 and differently aged AA6110 efficiently at applied stress amplitudes below a threshold stress amplitude at a given temperature where the near-surface work hardening states are unaltered and remain essentially constant, whereas compressive residual stress relax substantially during fatigue loading. On the other hand, above a threshold stress amplitude at a given temperature, deep rolling has no beneficial effect on the fatigue behavior of AA5083 and AA6110. This is a consequence of unstable near-surface work hardening states.

\section{References}

Altenberger, I. (2003). Alternative mechanical surface treatments: microstructures, residual stresses and fatigue behavior, In: Shot Peening, Wagner, L., (Ed.), pages 421-434, Wiley-VCH, ISBN 3527305378, Weinheim.

Coffin, L.F., (1997). A study of the effects of cyclic thermal stresses on a ductile metal, Trans ASME 76, pages 931-950.

Kohout, J., (2000). Temperature dependence of stress-lifetime fatigue curves, Fatigue $\mathcal{E}$ Fracture of Engineering Materials \& Structures, Vol. 23, No. 12, pages 969-977.

Löhe, D., Vöhringer, O. (2002). Stability of Residual Stresses, In: ASM International Handbook of Residual stress and Deformation of Steel, Totten, G., Howes, M., \& Inoue, T. (Ed.), pages 54-69, ASM International, ISBN 0-87170-729-2, USA.

Manson, S.S., (1966). Thermal stress and low cycle fatigue, McGraw-Hill, New York.

Scholtes, B. (1997). Assessment of residual stresses, In: Structural and Residual Stress Analysis by Nondestructive Methods, Hauk, V. (Ed.), pages 590-636, Elsevier, ISBN 978-0-44482476-9, Amsterdam.

Schulze, V., (2005). Modern Mechanical Surface Treatment, Wiley-VCH, Weinheim. 
Srivatsan, T.S. \& Coyne, E.J., Jr, (1986). Cyclic stress response and deformation behavior of precipitation-hardened aluminium-lithium alloys, International Journal of Fatigue, Vol. 8, No. 4, pages 201-208.

Srivatsan, T.S., (1991) The low-cycle fatigue and cyclic fracture behaviour of 7150 aluminium alloy, International Journal of Fatigue, Vol. 13, No. 4, pages 313-321.

Wagner, L., (1999). Mechanical surface treatments on titanium, aluminum and magnesium alloys, Materials Science and Engineering: A, Vol. 263, No. 2, pages 210-216. 


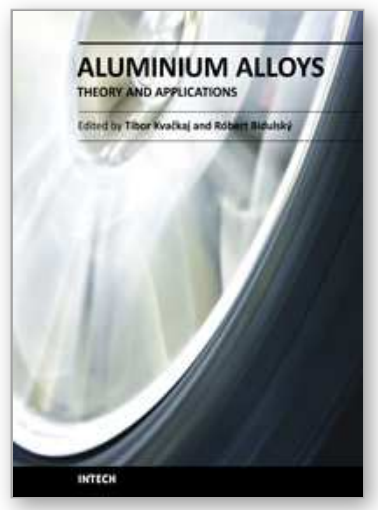

\author{
Aluminium Alloys, Theory and Applications \\ Edited by Prof. Tibor Kvackaj
}

ISBN 978-953-307-244-9

Hard cover, 400 pages

Publisher InTech

Published online 04, February, 2011

Published in print edition February, 2011

The present book enhances in detail the scope and objective of various developmental activities of the aluminium alloys. A lot of research on aluminium alloys has been performed. Currently, the research efforts are connected to the relatively new methods and processes. We hope that people new to the aluminium alloys investigation will find this book to be of assistance for the industry and university fields enabling them to keep up-to-date with the latest developments in aluminium alloys research.

\title{
How to reference
}

In order to correctly reference this scholarly work, feel free to copy and paste the following:

Patiphan Juijerm and Igor Altenberger (2011). Cyclic Deformation Behavior and Its Optimization at Elevated Temperature, Aluminium Alloys, Theory and Applications, Prof. Tibor Kvackaj (Ed.), ISBN: 978-953-307-244-9, InTech, Available from: http://www.intechopen.com/books/aluminium-alloys-theory-and-applications/cyclicdeformation-behavior-and-its-optimization-at-elevated-temperature

\section{INTECH}

open science | open minds

\section{InTech Europe}

University Campus STeP Ri

Slavka Krautzeka 83/A

51000 Rijeka, Croatia

Phone: +385 (51) 770447

Fax: +385 (51) 686166

www.intechopen.com

\section{InTech China}

Unit 405, Office Block, Hotel Equatorial Shanghai

No.65, Yan An Road (West), Shanghai, 200040, China

中国上海市延安西路65号上海国际贵都大饭店办公楼 405 单元

Phone: +86-21-62489820

Fax: $+86-21-62489821$ 
(C) 2011 The Author(s). Licensee IntechOpen. This chapter is distributed under the terms of the Creative Commons Attribution-NonCommercialShareAlike-3.0 License, which permits use, distribution and reproduction for non-commercial purposes, provided the original is properly cited and derivative works building on this content are distributed under the same license. 